Mei Fitria Kurniati, Mohammad Roni Al-Faqih. Hubungan Usia dan Jenis Kelamin dengan Kepatuhan Kontrol Gula Darah Puasa Pasien Diabetes Mellitus di Puskesmas Ngraho

\title{
HUBUNGAN USIA DAN JENIS KELAMIN DENGAN KEPATUHAN KONTROL GULA DARAH PUASA PASIEN DIABETES MELLITUS DI PUSKESMAS NGRAHO
}

\author{
Mei Fitria Kurniati ${ }^{1}$ \\ STIKes Insan Cendekia Husada Bojonegoro \\ Corresponding Author Email : meiok978@gmail.com \\ Mohamad Roni Alfaqih ${ }^{2}$ \\ STIKes Insan Cendekia Husada Bojonegoro \\ Corresponding Author Email : alfaqih817@yahoo.com
}

\begin{abstract}
ABSTRAK
Diabetes Mellitus dikenal sebagai silent killer karena sering tidak disadari oleh penyandangnya dan ketika diketahui sudah terjadi komplikasi. Salah satu faktor yang penting dalam menyikapi penyakit diabetes mellitus pada seseorang adalah faktor kepatuhan. Diabetes Mellitus dapat menyerang hampir semua sistem tubuh manusia, mulai dari kulit sampai jantung yang menimbulkan komplikasi. Tujuan penelitian yaitu mengetahui hubungan usia dan jenis kelamin dengan kepatuhan kontrol kadar gula darah puasa pasien diabetes mellitus di Puskesmas Ngraho.

Desain penelitian menggunakan metode kuantitatif dengan pendekatan Cross Sectional. Variabel independen yaitu usia dan jenis kelamin dan variabel dependennya yaitu kepatuhan kontrol kadar gula darah. Populasi dalam penelitian ini yaitu pasien DM yang melakukan kontrol bulan April-Agustus 2021 sejumlah 32 dengan menggunakan Total sampling.

Hasil penelitian menunjukkan tidak ada hubungan Usia dengan Kepatuhan Kontrol Gula Darah Pasien Diabetes Mellitus dengan nilai P- value 0.91. Tidak ada hubungan Jenis Kelamin dengan Kepatuhan Kontrol Gula Darah Pasien Diabetes Mellitus dengan nilai P-value 0.681 .

Kepatuhan kontrol merupakan hal penting untuk keberhasilan dalam menjalankan dan mengendalikan kadar gula darah. Hal ini menjadi tugas penting perawat untuk meningkatkan kesadaran dan motivasi penderita diabetes mellitus agar selalu melakukan kontrol kesehatannya sehingga bisa mencegah terjadinya komplikasi.
\end{abstract}

Kata Kunci : Umur, Jenis Kelamin, Diabetes Mellitus, Kepatuhan Kontrol

\section{ABSTRACT}

Diabetes Mellitus is known as the silent killer it because of not realized by the sufferer and when it is known that complications have occurred. One of the important factors in addressing diabetes mellitus in a person is the compliance factor. Diabetes Mellitus can attack almost all systems of the human body, from the skin to the heart which causes complications. The purpose of the study was to determine the relationship between age and gender with blood sugar control compliance in patients with diabetes mellitus at the Ngraho Public Health Center.

The research design uses quantitative methods with a Cross Sectional approach with data secunder. The independent variables are age and gender and the dependent variable is the compliance of blood sugar level control. The population in this study were all $32 \mathrm{DM}$ patients who took control in April-August 2021 using total sampling.

The results showed that there was no relationship between Age and Blood Sugar Control Compliance in Diabetes Mellitus Patients with a P-value of 0.91. There is no relationship between Gender and Compliance with Blood Sugar Control in Diabetes Mellitus Patients with a P-value of 0.681.

Compliance control is an important aspect for success in running and controlling blood sugar levels. This is an important task for nurses to increase awareness and motivation of people with diabetes mellitus to always control their health so that they can prevent complications

Keywords : Age, Gender, Diabetes Mellitus, Blood Sugar Compliance

\section{PENDAHULUAN}

Diabetes mellitus Tipe 2 (DMT2) merupakan kasus yang banyak ditemukan dan terhitung sekitar $90 \%$ kasus dari semua DM yang ada di dunia (Kalyani dkk, 2017). Laporan dari Centers for Disease Control and 
Prevention (CDC) 2017, menyebutkan sebanyak 30,3 juta penduduk di Amerika Serikat mengalami DM (Gao et al, 2016). Laporan dari International Diabetes Federation (IDF) 2017, memprediksi adanya peningkatan jumlah penderita DM di dunia dari 425 juta jiwa pada tahun 2017, menjadi 629 juta jiwa pada tahun 2045. Sedangkan di Asia Tenggara, dari 82 juta pada tahun 2017 , menjadi 151 juta pada tahun 2045. Indonesia merupakan negara ke- 7 dari 10 besar negara yang diperkirakan mempunyai jumlah penderita DM sebesar 5,4 juta pada tahun 2045 serta mempunyai angka kendali kadar gula darah yang rendah (Artha et all, 2019). Kondisi gawat darurat dapat terjadi dimana saja, kapan saja dan dapat menimpa siapa saja serta tidak bisa diprediksi secara tepat waktu terjadinya (Pusponegoro, 2011 dalam Khayudin, B. A, 2020 ).

Prevalensi diabetes mellitus di provinsi Jawa Timur dalam Riskesdas (Riset Kesehatan Dasar) tahun 2018 adalah 113.045 ribu jiwa. Bersadarkan data dari Dinkes Kabupaten Bojonegoro menyebutkan bahwa prevalensi penyakit diabetes mellitus pada tahun 2018 per puskesmas adalah 13.782 jiwa untuk NIDDM (Non Insulin Dependent Diabetes Mellitus) dan 4560 jiwa untuk IDDM (Insulin Dependent Diabetes Mellitus. Berdasarkan data di puskesmas Ngraho saat ini penderita diabetes mellitus tahun 2020 sejumlah 260 pasien. Selanjutnya data tentang jumlah pasien yang melakukan kontrol selama 3 bulan terakhir yaitu pada bulan November 2020 sejumlah 63 pasien, bulan Desember 2020 terdapat 61 pasien sementara bulan januari 2021 sejumlah 63 pasien.

Menurut konsensus Perhimpunan Endoktrinologi Indonesia (PERKENI, 2015), pilar pengendalian diabetes mellitus meliputi latihan jasmani, terapi gizi medis, intervensi farmakologis, dan edukasi. Keberhasilan proses kontrol terhadap penyakit diabetes mellitus salah satunya ditentukan oleh kepatuhan pasien dalam mengelola pola makan atau diet sehari-hari. Hal ini agar mencegah timbulnya komplikasi dari diabetes mellitus. Menurut Di Matteo (2004) menunjukkan bahwa populasi penderita diabetes mellitus adalah populasi yang terendah kepatuhan $(67,5 \%)$ dalam tindakan medis yang dianjurkan dibandingkan 16 penyakit utama lain. Pasien DM membutuhkan waktu untuk beradaptasi dengan baik terhadap perubahan gaya hidup. Pencegahan dan strategi penatalaksanaan menjadi sangat penting dalam pemantauan diabetes mellitus. Pemantauan dan penatalakasanaan DM yang maksimal akan memberikan dampak positif terhadap kesehatan, terutama terhadap kualitas hidup dan usia harapan hidup (Sikdar, K. C., Wang, P. P., MacDonald, D., \& Gadag, V. G, 2010 dalam Ferawati, \& Kurniati, M. F, 2019)

Ada beberapa yang bisa mempengaruhi kepatuhan kontrol meliputi faktor internal diantaranya usia, jenis kelamim, pengetahuan, peran keluarga, dukungan keluarga, dukungan sosial. Dilihat dari kenyataan dilapangan bahwa penderita Diabetes Mellitus sering dating kontrol ke Puskesmas dengan keluhan mata kabur, badan terasa gatal, sering terbangun dan kencing sering pada malam hari, dengan berat badan turun sedangkan konsumsi makanan banyak. Padahal mereka yang datang ke Puskesmas mayoritas penderita diabetes mellitus cukup lama ( \pm 1 tahun) petugas puskesmas menanyakan tentang makanan apa yang sudah dikonsumsi sehingga sampai selalu muncul kembali. Biasanya seseorang yang menderita penyakit diabetes mellitus memiliki kekambuhan pada penderita diabetes mellitus yang datang ke pusat pelayanan kesehatan mengalami kekambuhan seperti keluar keringat dingin,kulit gatal dII (Fauzia, 2016 dalam Hestiana 2017).

Kepatuhan kontrol merupakan hal penting untuk keberhasilan dalam menjalankan dan mengendalikan kadar gula darah. Bila pasien Diabetes Mellitus dapat mematuhi jadwal kontrolnya maka akan membantu dalam pengendalian tingkat kadar gula darahnya karena dengan kepatuhan kontrol tersebut dapat membantu proses penyembuhan dan pencegahan komplikasi (Irmansyah, 2020).

Kendala utama pada penanganan diet diabetes mellitus adalah kejenuhan pasien dalam mengikuti kontrol yang diperlukan untuk mencapai keberhasilan. Meskipun diperlukan pola makan atau diet yang sesuai dengan perintah dokter, namun kenyataannya tingkat kepatuhan pasien dalam menjalankan program manajemen penyakit tidak cukup baik. Permasalahan seperti ini menjadi tantangan dalam penanggulangan penyakit diabetes melitus (Hestiana, 2017). 
Mei Fitria Kurniati, Mohammad Roni Al-Faqih. Hubungan Usia dan Jenis Kelamin dengan Kepatuhan Kontrol Gula Darah Puasa Pasien Diabetes Mellitus di Puskesmas Ngraho

Diabetes melitus merupakan penyakit yang tidak bisa disembuhkan, namun dapat dikontrol. Pasien yang tidak patuh terhadap prinsip kontrol dan perencanaan kontrol merupakan kendala utama pada pasien diabetes mellitus. Oleh karena itu, dalam manajemen penyakit diabetes mellitus, selain dokter, perawat, ahli gizi, dan tenaga kesehatan lain, peran pasien dan dukungan keluarga menjadi sangat penting (Perkeni, 2015). Hal ini menjadi tugas penting perawat untuk meningkatkan kesadaran dan motivasi penderita diabetes mellitus agar selalu melakukan kontrol kesehatannya sehingga bisa mencegah terjadinya komplikasi yang tidak diinginkan dan perkembangan penyakit akan terus terpantau.

\section{Tujuan Penelitian}

Tujuan Umum

Untuk mengetahui hubungan usia dan jenis kelamin dengan kepatuhan kontrol gula darah pasien diabetes mellitus

Tujuan Khusus

a. Mengidentifikasi usia dan jenis kelamin pasien diabetes mellitus

b. Mengidentifikasi kepatuhan kontrol gula darah

c. Menganalisis hubungan usia dan jenis kelamin dengan kepatuhan kontrol gula darah pasien diabetes mellitus

\section{METODE PENELITIAN}

Desain yang digunakan dalam penelitian ini cross sectional. Populasi penelitian lini adalah seluruh pasien diabetes mellitus yang melakukan kontrol di puskesmas Ngraho pada bulan Januari 2020-Desember 2020 sejumlah 32 responden. Sampel yang dipakai dalam penelitian ini yaitu 32 pasien.

Teknik sampling dalam penelitian yaitu Total Sampling yaitu pengambilan sampel dengan cara memilih semua sampel dari populasi sesuai dengan yang dikehendaki peneliti (tujuan/masalah dalam penelitian) (Nursalam, 2020). Variabel independen yaitu usia dan jenis kelamin. Variabel dependen adalah kepatuhan kontrol.

Instrumen pada penelitian ini menggunakan data sekunder berupa data usia, jenis kelamin, kunjungan kontrol pasien diabetes mellitus di puskesmas Ngraho pada bulan Januari 2020-Desember 2020. Selanjutnya data di olah dan di analisis menggunakan uji Spearman Rho

\section{HASIL}

\section{Data Umur Pasien}

Tabel 1 Distribusi Frekuensi Responden Berdasarkan Usia Pasien Diabetes di Puskesmas Ngraho

\begin{tabular}{cccc}
\hline No & Usia & Frekuensi & $\begin{array}{c}\text { Prosentase } \\
\%\end{array}$ \\
\hline 1 & $\begin{array}{c}\text { Dewasa Awal } \\
\text { (26-35 tahun) }\end{array}$ & 2 & 6.2 \\
\hline 2 & $\begin{array}{c}\text { Dewasa Akhir } \\
\text { (36-45 tahun) }\end{array}$ & 7 & 21.9 \\
\hline 3 & $\begin{array}{c}\text { Lansia Awal } \\
\text { (46-55 tahun) }\end{array}$ & 17 & 53.1 \\
\hline 4 & $\begin{array}{c}\text { Lansia Akhir } \\
\text { (56-65 tahun) }\end{array}$ & 6 & 18.8 \\
\hline & Jumlah & 32 & 100 \\
\hline
\end{tabular}

Sumber : Data Sekunder 2020

Berdasarkan tabel 1 didapatkan dari 32 responden sebagian besar berumur 46-55 tahun (lansia awal) yaitu sejumlah 17 responden $(53,1 \%)$.

\section{Data Jenis Kelamin Pasien}

Tabel 2 Distribusi Frekuensi Responden berdasarkan Jenis Kelamin Pasien Diabetes Mellitus di Puskesmas Ngraho

\begin{tabular}{cccc}
\hline No & $\begin{array}{c}\text { Jenis } \\
\text { Kelamin }\end{array}$ & Frekuensi & $\begin{array}{c}\text { Prosentase } \\
\%\end{array}$ \\
\hline 1 & Laki-laki & 7 & $\mathbf{2 1 . 9}$ \\
\hline 2 & Perempuan & 25 & $\mathbf{7 8 . 1}$ \\
\hline \multicolumn{2}{l}{ Jumlah } & & $\mathbf{1 0 0}$ \\
\hline
\end{tabular}

Sumber : Data Sekunder 2020

Berdasarkan tabel 2 menunjukkan bahwa dari 32 pasien hampir seluruhnya jenis kelaminnya adalah perempuan yaitu sejumlah 25 responden (78,1 \%).

\section{Data Kepatuhan Kontrol Gula Darah Pasien Diabetes Mellitus}

Tabel 3 Distribusi Frekuensi

Berdasarkan Kepatuhan Kontrol Gula

Darah Pasien Diabetes Mellitus di Puskesmas Ngraho

\begin{tabular}{cccc}
\hline No & $\begin{array}{c}\text { Kepatuh } \\
\text { an } \\
\text { Kontrol }\end{array}$ & $\begin{array}{c}\text { Frekuen } \\
\text { si }\end{array}$ & Prosentase \% \\
\hline 1 & Patuh & 16 & 50.0 \\
\hline 2 & $\begin{array}{c}\text { Tidak } \\
\text { Patuh }\end{array}$ & 16 & 50.0 \\
\hline & Jumlah & 32 & 100 \\
\hline
\end{tabular}


Sumber : Data Sekunder 2020

Berdasarkan tabel 3 menunjukkan bahwa sebagian responden patuh melakukan kontrol sejumlah 16 responden $(50 \%)$ dan 16 responden tidak patuh melakukan kontrol 16 responden (50\%).

4. Hasil Korelasi Hubungan Usia dan Jenis Kelamin dengan kepatuhan kontrol gula darah pasien Diabetes Mellitus

Tabel 4 Hasil Korelasi hubungan usia dan jenis kelamin dengan kepatuhan kontrol pasien diabetes mellitus

\begin{tabular}{|c|c|c|c|c|c|c|}
\hline \multirow[t]{3}{*}{ Usia } & \multicolumn{3}{|c|}{ Kepatuhan } & \multicolumn{2}{|c|}{ Total } & \multirow[b]{2}{*}{$p$} \\
\hline & \multicolumn{2}{|c|}{ Patuh } & \multicolumn{2}{|c|}{$\begin{array}{l}\text { Tidak } \\
\text { Patuh }\end{array}$} & & \\
\hline & $N$ & $\%$ & $N$ & $\%$ & $N$ & $\%$ \\
\hline $\begin{array}{l}\text { Dewasa } \\
\text { Awal }\end{array}$ & 1 & 3.1 & 1 & 3.1 & 2 & 6.2 \\
\hline $\begin{array}{l}\text { Dewasa } \\
\text { Akhir }\end{array}$ & 5 & 15.6 & 2 & 6.2 & 7 & $\begin{array}{c}21 . \\
8\end{array}$ \\
\hline $\begin{array}{l}\text { Lansia } \\
\text { Awal }\end{array}$ & 9 & 28.1 & 8 & 25 & 17 & $\begin{array}{c}53 . \\
1\end{array}$ \\
\hline $\begin{array}{l}\text { Lansia } \\
\text { Akhir }\end{array}$ & 1 & 3.1 & 5 & $\begin{array}{c}15 . \\
6\end{array}$ & 6 & $\begin{array}{c}18 . \\
7\end{array}$ \\
\hline Total & 16 & 50 & 16 & 50 & 32 & 100 \\
\hline
\end{tabular}

Berdasarkan hasil uji Spearman Rho, ditujukkan bahwa hasil nilai P- value pada kolom sig ( 2 tailed ) didapatkan nilai 0.91 lebih besar dari level of significant a 0,05 ( $0,91>0,05$ ) maka dapat disimpulkan yaitu $\mathrm{H}_{0}$ di diterima dan $\mathrm{H}_{1}$ ditolak. Berarti tidak ada hubungan Usia dengan Kepatuhan Kontrol Gula Darah Pasien Diabetes Mellitus

Tabel 5 Hasil Korelasi hubungan jenis kelamin dengan kepatuhan kontrol gula darah pasien diabetes mellitus

\begin{tabular}{lccccccc}
\multicolumn{1}{c}{$\begin{array}{c}\text { Jenis } \\
\text { Kelam } \\
\text { in }\end{array}$} & \multicolumn{3}{c}{ Kepatuhan } & \multicolumn{3}{c}{ Total } \\
\cline { 2 - 8 } & \multicolumn{4}{c}{$\begin{array}{c}\text { Tidak } \\
\text { Patuh }\end{array}$} \\
\cline { 2 - 8 } & $N$ & $\%$ & $N$ & $\%$ & $N$ & $\%$ & \\
\hline Laki- & 3 & 9.4 & 4 & 1 & 7 & 21.9 & 0 \\
laki & & & & 2. & & & 2. \\
& & & & 5 & & & \\
\hline Perem & 13 & 40. & 12 & 3 & 2 & 73.1 & \\
puan & & 6 & & 7. & 5 & & \\
& & & & 5 & & & \\
\hline Total & 16 & 50 & 16 & 5 & 3 & 100 \\
& & & & 0 & 2 & \\
\hline
\end{tabular}

Berdasarkan hasil uji Spearman Rho, ditunjukkan bahwa hasil nilai $\mathrm{P}$ - value pada kolom sig ( 2 tailed ) didapatkan nilai 0.681 lebih besar dari level of significant a 0,05 ( $0,681>0,05$ ) maka dapat disimpulkan $\mathrm{H}_{0}$ di diterima dan $\mathrm{H}_{1}$ ditolak. Berarti tidak ada hubungan Jenis Kelamin dengan Kepatuhan Kontrol Gula Darah Pasien Diabetes Mellitus

\section{PEMBAHASAN}

\section{Usia}

Berdasarkan tabel 1 menunjukkan sebagian besar responden $(53,1 \%)$ berumur 46-55 tahun sejumlah 17 responden. Menurut Perkeni (2015) resiko berkembang penyakit diabetes mellitus meningkat seiring dengan bertambahnya umur. Selain itu juga, sejumlah perubahan akan terjadi dengan bertambahnya usia, termasuk anatomi, fisiologi, psikologi dan sosiologi. Califano mengemukakan bahwa usia merupakan solgh satu faktor resiko terjadinya masalah kesehatan seperti penyakit diabetes mellitus. Insiden penyakit diabetes mellitus meningkat seiring dengan pertambahan umur (Suyono, 2011).

Rochmah (2006) menjelaskan prevalensi penyakit diabetes mellitus lebih tinggi didapatkan pada usia dewasa, dimana pada usia dewasa (30 tahun) kadar glukosa darah mengalami kenaikan $1-2 \mathrm{mg} /$ tahun pada saat puasa dan akan naik sekitar $5,6-13 \mathrm{mg}$ pada 2 jam setelah makan. Pasien diabetes mellitus di Indonesia kebanyakan beusia antara 45 sampai 64 tahun. Seiring dengan bertambahnya usia maka seseorang yang menderita diabetes mellitus perlu teratur melakukan kontrol agar mengetahui perkembangan penyakitnya. Pasien diabetes mellitus yang teratur melakukan kontrol akan mendapatkan edukasi dan dukungan dari tenaga kesehatan dalam pengontrolan gPla darah sehingga mencegah dan menghambat timbulnya penyulit kronik ataupun akut.

\section{81 enis Kelamin}

Berdasarkan tabel 2 didapatkan dari 32 pasien hampir semuanya berjenis kelamin perempuan yaitu sejumlah 25 responden ( 78,1 \%).

Hasil penelitian Adisa (2011) dalam Sucipto \& Rosa (2017) yang menyatakan bahwa laki-laki cenderung lupa untuk kontrol dan meminum obat dan pasien yang bekerja dengan tingkat pendidikan 
yang tinggi mempunyai kecenderungan untuk lebih ingat untuk kontrol dan meminum obat dibandingkan dengan pasien yang tidak bekerja. Hal ini sesuai dengan karakteristik responden dalam penelitian yang telah dilakukan dimana jumlah reponden perempuan lebih banyak yaitu 25 responden $(78,1 \%)$ jika dibandingkan dengan responden laki-laki yang jumlahnya 7 responden $(21,9 \%)$. Diabetes mellitus yaitu penyakit kronis yang berlangsung lama, agar proses dalam pengobatannya dapat berjalan baik, kerja sama pasien diabetes mellitus dan keluarga dengan penyedia layanan kesehatan, khususnya dokter harus terjalin baik. Diabetes termasuk penyakit yang belum bisa disembuhkan, yang bisa dilakukan yaitu mengendalikan dan mengontrol penyakitnya sehingga dapat mempertahankan kualitas hidup.

\section{Kepatuhan Kontrol}

Berdasarkan tabel 3 menunjukkan dari 32 responden didapatkan 16 responden (50 \%) patuh melakukan kontrol dan 16 responden (50\%) tidak patuh melakukan kontrol. Pada dasarnya individu berperan penting pada perilaku kepatuhan, hal ini dikarenakan segala apa yang dilakukannya adalah dari keputusan individu itu sendiri. Faktorfaktor luar hanya sebagai pendukung dari perilaku kepatuhan tersebut.

Dari 32 responden, diperoleh data penelitian yaitu 16 responden (50\%) tidak patuh melakukan kontrol. Banyaknya proporsi responden tidak patuh dalam melakukan kontrol gula darah dipengaruhi oleh beberapa hal. Menurut Handayani dan Faidah (2014), faktor yang menjadi dasar terkait meningkatnya responden yang tidak patuh dalam melakukan kontrol gula darah adalah pendidikan, pengetahuan, dukungan keluarga serta tingkat ekonomi penderita.

Pada dasarnya pasien diabetes mellitus yang tidak rutin melakukan kontrol karena kurangnya dukungan keluarga dalam memperhatikan jadwal kontrol dan tidak ada waktu mengantar pasien ke klinik, perilaku responden yang merasa sudah sembuh total dan tidak ada keluhan sehingga memutuskan tidak mematuhi jadwal kontrol, pasien merasa jenuh datang ke pelayanan kesehatan untuk berobat rutin serta responden enggan kontrol karena kondisi antrian yang banyak sehingga waktu kontrol menjadi lama dan membosankan.

4. Hubungan Usia dengan Kepatuhan Kontrol Gula Darah Puasa Pasien Diabetes Mellitus di Puskesmas Ngraho

Berdasarkan hasil uji Spearman $R h o$, ditujukkan bahwa hasil nilai $P$ - value pada diperoleh nilai 0.91 lebih besar dari level of significant $\alpha$ 0,05 $(0,91>0,05)$ sehingga disimpulkan $\mathrm{H}_{0}$ di diterima dan $\mathrm{H}_{1}$ ditolak. Berarti tidak ada hubungan Usia dengan Kepatuhan Kontrol Gula Darah Pasien Diabetes Mellitus.

Kepatuhan seseorang dalam menjalani pengobatan seringkali terganggu dengan beberapa pantangan dalam pengobatan tersebut, misalnya masalah makanan yang lebih rentan terjadi dalam menjaga kestabilan kadar gula darah seseorang. Pengendalian diri dan dari lingkungan luar berpengaruh dalam tingkat kepatuhan seseorang (Safitri, 2013). Seseorang yang telah patuh menjalani kontrol dan pengobatan, perlu juga memperhatikan diet makanan, aktivitas, olahraga dan menghindari stres untuk menjaga kestabilan gula darah.

Beberapa penelitian menyatakan bahwa pasien dengan usia yang lebih tua lebih patuh terhadap kontrol berobat dibandingkan pasien muda. Penelitian lain juga menyatakan bahwa pasien geriatri lebih beresiko tidak patuh kontrol karena mereka tidak mengerti regimen obat dan sering kali lupa serta memiliki masalah penglihatan, pendengaran, dan kognitif dengan prevalensi yang lebih besar dibandingkan pasien dengan umur yang lebih muda (Khan dkk, 2009 dalam Sucipto \& Rosa , 2017).

Penelitian ini sejalan dengan penelitian Liu (2004) dalam Hestiana (2017) mempelajari kemampuan orang dewasa yang lebih tua untuk mengingat dalam memonitor glukosa mereka sebanyak empat kali dalam waktu yang telah ditentukan. Dalam penelitiannya menyatakan bahwa tidak ada hubungan antara usia dengan kepatuhan dalam pengelolaan kepatuhan diet DM.

Hal ini tidak sejalan dengan penelitian Trisnawati (2013) bahwa adanya hubungan yang signifikan pada 
kelompok usia lebih dari 45 tahun yang lebih beresiko menderita DM tipe 2 . Didapatkan hasil penderita DM lebih banyak pada kelompok umur dewasa daripada lansia. Dengan bertambahnya usia maka terjadi penurunan fungsi pendengaran, penglihatan dan daya ingat seorang pasien sehingga pada pasien usia lanjut akan lebih sulit menerima informasi dan akhirnya salah paham mengenai instruksi yang diberikan oleh petugas kesehatan.

5. Hubungan Jenis Kelamin dengan Kepatuhan Kontrol Gula Darah Puasa Pasien Diabetes Mellitus di Puskesmas Ngraho

Berdasarkan hasil uji Spearman Rho, ditunjukkan bahwa hasil nilai $\mathrm{P}$ value didapatkan nilai 0.681 lebih besar dari level of significant $\alpha$ 0,05 (0,681 > 0,05 ) maka dengan demikian dapat disimpulkan bahwa $\mathrm{H}_{0}$ di diterima dan $\mathrm{H}_{1}$ ditolak. Berarti tidak ada hubungan Jenis Kelamin dengan Kepatuhan Kontrol Gula Darah Pasien Diabetes Mellitus

Penelitian yang sejalan yaitu dalam penelitian Tania (2016) menunjukkan persentase responden yang ikut dalam penelitian dengan jenis kelamin pria lebih banyak $(51 \%)$ dibandingkan perempuan (49\%). Namun, pada uji statistik Tania (2016) dalam Hestiana (2017) didapatkan tidak ada hubungan jenis kelamin dengan kepatuhan diet pada pasien diabetes mellitus tipe 2 . Ketidakbermaknaan antara jenis kelamin dengan kepatuhan diet dapat disebabkan karena jenis kelamin bukan merupakan faktor yan berhubungan langsung dengan perilaku kepatuhan seperti yang diungkapkan dalam teori Health Belief Model atau model kepercayaan kesehatan. Penelitian lain yang sejalan adalah menurut Nugroho (2017) menyatakan dalam penelitiannya bahwa tidak ada hubungan yang bermakna antara jenis kelamin dengan kepatuhan diet penderita DM dengan jumlah laki-laki sebanyak $77 \%$ lebih patuh daripada perempuan sebanyak $50,8 \%$ patuh.

Perbedaan jenis kelamin dalam melakukan kontrol tidak menjadi suatu masalah. Karena responden yang berjenis kelamin wanita maupun laki-laki sangat penting untuk melakukan kontrol agar dapat mencegah timbulnya komplikasi. Menurut Riset kesehatan dasar (2013) prevalensi wainita lebih tinggi daripada pria, hal ini dikarenakan beberapa faktor risiko menyebabkan tingginya kejadian diabetes mellitus pada wanita.

Edukasi pasien merupakan salah satu pilar penting dalam kontrol dan pengelolaan diabetes mellitus agar mengoptimalkan terapi pengobatan. Jika edukasi dijalankan secara efektif, dapat meningkatkan kepatuhan dan pengelolaan diri sendiri oleh pasien terhadap penyakitnya (Farsaei, S., dkk, 2011 dalam Sucipto \& Rosa 2017).

WHO pada tahun 2006 menyatakan bahwa perawat memegang peranan yang penting untuk membantu mengatasi masalah kepatuhan yang rendah terhadap diit jangka panjang pada penyakit kronik, seperti diabetes mellitus. Perawat merupakan posisi yang tepat untuk memberikan edukasi kepada pasien tentang diit yang benar, menjelaskan pentingnya pengontrolan gula darah untuk untuk meningkatkan kepatuhan dan meminimalkan timbulnya komplikasi jangka panjang karena perawat senantiasa berhubungan dengan pasien selama 24 jam dan lebih memahami keadaan pasien (Donoan dkk 2011 dalam Sucipto \& Rosa, 2017).

\section{KESIMPULAN}

1. Sebagian besar berumur $46-55$ tahun (lansia awal) yaitu sejumlah 17 responden $(53,1 \%)$

2. Hampir seluruhnya berjenis kelamin wanita sejumlah 25 responden $(78,1 \%)$.

3. Sebagian responden patuh melakukan kontrol sejumlah 16 responden (50\%) dan 16 responden tidak patuh melakukan kontrol 16 responden $(50 \%)$.

4. Tidak ada hubungan Usia dengan Kepatuhan Kontrol Gula Darah Pasien Diabetes Mellitus dengan nilai P- value 0.91 lebih besar dari level of significant $\alpha$ $0,05(0,91>0,05)$

5. Tidak ada hubungan Jenis Kelamin dengan Kepatuhan Kontrol Gula Darah Pasien Diabetes Mellitus dengan hasil nilai $P$ - value 0.681 lebih besar dari level of significant $\alpha 0,05(0,681>0,05)$.

\section{SARAN}

1. Bagi Responden 
Mei Fitria Kurniati, Mohammad Roni Al-Faqih. Hubungan Usia dan Jenis Kelamin dengan Kepatuhan Kontrol Gula Darah Puasa Pasien Diabetes Mellitus di Puskesmas Ngraho

Diharapkan responden mampu meningkatkan kepatuhan kontrol dan memperhatikan kondisi kesehatannya mulai dari faktor pola makan, aktivitas olahraga, stres untuk mencegah komplikasi penyakit

2. Bagi layanan kesehatan

Hendaknya layanan kesehatan mengupayakan kerjasama yang baik antara tenaga kesehatan dengan pasien beserta keluarga untuk berperan aktif dalam memberikan dukungan dan edukasi pada pasien diabetes mellitus tentang melakukan diet yang benar, kontrol gula darah, mengelola stres, menjaga aktivitas olahraga yang tepat dan menjalankan pengobatan farmakologis.

3. Institusi Pendidikan

Institusi pendidikan dapat meningkatkan kualitas pengembangan kurikulum melalui penambahan literatur, khusus yang berkaitan dengan kepatuhan kontrol sekaligus terkait faktor-faktor yang mempengaruhi keberhasilan perawatan dan pengendalian penyakit diabetes mellitus.

4. Peneliti selanjutnya

Diharapkan hasil penelitian ini bisa digunakan untuk acuan untuk melakukan penelitian dan sebagai pertimbangan bagi peneliti yang akan datang tentang hal-hal yang berhubungan dengan usia , jenis kelamin dan kepatuhan kontrol

\section{DAFTAR PUSTAKA}

Artha, IMJR., Bhargah, A., Dharmawan, NK., Pande, UW,, Triyana, KA., Mahariski, PA., et al. (2019). High level of individual lipid profile and lipid ratio as a predictive marker of poor glycemic control in type2 diabetes mellitus. Vasc Health Risk Manag. Volume 15:149-157.

Handayani, N \& Faidah, N. (2014). FaktorFaktor yang Berhubungan dengan Kepatuhan Kontrol Gula Darah Penderita Diabetes Melitus di RSUD Kelet Jepara. Jurnal Keperawatan dan Kesehatan Masyarakat Cendikia Utama. Volume 3, No 2

Hestiana, D. W. (2017). Faktor-faktor yang berhubungan dengan kepatuhan dalam pengelolaan diet pada pasien rawat jalan diabetes mellitus tipe 2 di Kota Semarang. JHE (Journal of Health Education), 2(2), 137-145.

Irmansyah. (2020).Hubungan Kepatuhan Kontrol Dengan Kadar Gula Darah Sewaktu Pada Pasien Dm Tipe 2 Mahakam Nursing Journal. Vol 2. No. 8, 363-372

Kalyani, RR., Golden. SH., Cefalu, WT. (2017). Diabetes and Aging: Unique Considerations and Goals of Care. Diabetes Care. Volume 40(4):440-443

Kemenkes RI.(2018). Hasil Utama Riskesdas 2018. Jakarta: Kemenkes RI

Khayudin, B. A. (2020).Pengalaman Masyarakat Sebagai Penolong Awam Dalam Memberikan Pertolongan Kepada Korban Kecelakaan lalu lintas Kabupaten Bojonegoro. Jurnal IImu Kesehatan MAKIA, 10(2), 62-65.

Ferawati, \& Kurniati, M. F. (2019). Relationship Between Family Support and Self Care Agency with the Quality of Living Type II Diabetes Patients. Journal Of Nursing Practice, 3(1), 22-32.

Nugroho, Edwin Rheza., Warlisti, Ika Vemilia., Bakri, Saekhol. (2018) Hubungan Dukungan Keluarga Dengan Kepatuhan Kunjungan Berobat Dan Kadar Glukosa Darah Puasa Penderita Diabetes Melitus Tipe 2 Di Puskesmas Kendal 1. Jurnal Kedokteran Diponegoro, 7(4)

Nursalam. (2020). Metodologi Penelitian IImu Keperawatan: Pendekatan Praktis.Ed. 5. Jakarta: Salemba Medika

Perkumpulan Endokrinologi Indonesia. 2015.Konsensus Pengelolaan dan Pencegahan Diabetes Melitus Tipe 2 
Mei Fitria Kurniati, Mohammad Roni Al-Faqih. Hubungan Usia dan Jenis Kelamin dengan Kepatuhan Kontrol Gula Darah Puasa Pasien Diabetes Mellitus di Puskesmas Ngraho

di Indonesia 2015. Jakarta: PB PERKENI.

Rochmah W. (2006). Diabetes Melitus Pada Usia Lanjut. Jakarta: Depertemen IImu Penyakit Dalam Fakultas Kedokteran Universitas Indonesia

Safitri, I. N. (2013). Kepatuhan penderita diabetes mellitus tipe II ditinjau dari locus of control. Jurnal IImiah Psikologi Terapan, 1(2), 273-290.

Sucipto, Adi \& Rosa, Elsye Maria. (2017). Efektivitas Konseling diabetes mellitus dalam Meningkatkan Kepatuhan dan Pengendalian Gula Darah pada Diabetes Melitus Tipe 2

Suyono, dkk. (2011). Kecendrungan Peningkatan Jumlah Penyandang Diabetes. Jakarta: Balai Penerbit FK UI.

Trisnawati, S. K.., \& Setyorono, S. (2013). Faktor Risiko Kejadian Diabetes Mellitus Tipe 2 di Puskesmas Kecamatan Cengkareng Jakarta Barat Tahun 2012. Jurnal IImiah Kesehatan, 5 (1): 1-11 